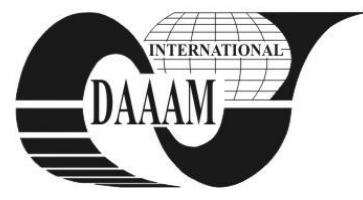

Annals of DAAAM for 2011 \& Proceedings of the 22nd International DAAAM Symposium, Volume 22, No. 1, ISSN 1726-9679 ISBN 978-3-901509-83-4, Editor B. Katalinic, Published by DAAAM International, Vienna, Austria, EU, 2011 Make Harmony between Technology and Nature, and Your Mind will Fly Free as a Bird Annals \& Proceedings of DAAAM International 2011

\title{
VISUAL INSPECTION OF LASER WELDED NI-CR DENTAL ALLOYS
}

\author{
POROJAN, S[orin]; SANDU, L[iliana] \& TOPALA, F[lorin] I[onel]
}

\begin{abstract}
Minor problems arising from optimizations by welding of fixed prostheses frameworks can be identified by macroscopic and microscopic visual inspection. The purpose of this study was to highlight the visible discontinuities present in the laser welds of dental $\mathrm{Ni}-\mathrm{Cr}$ alloys. $\mathrm{Ni}$-Cr base metal alloys designated for fixed prostheses manufacture were selected for the experiments. Using cast plates, preliminary tests were conducted by laser welding. Macroscopic visual inspection was done carefully to assess the defects of the welding rib. Electron microscopy images allowed visualization of small discontinuities, which escapes visual inspection. Making comparison to $\mathrm{Ni}-\mathrm{Cr}$ alloys taken in the experiment and laser welded, after visual analysis, the best welds appear for Heraenium NA alloy

Key words: macroscopic visual inspection, electron microscopy, $\mathrm{Ni}-\mathrm{Cr}$ dental alloys, laser welding, prostheses
\end{abstract}

\section{INTRODUCTION}

Minor problems arising from optimizations by welding of fixed prostheses frameworks can be identified and corrected before the completion of the weld (Jeffus, 2008).

Macroscopic visual inspection is important to assess aspects of welding rib. To highlight the discontinuities which are not visible to the eye, optical or electronic microscopy may be used.

When assessing a weld it is important to note the type of discontinuity, its size and location. Each of these factors and all together are decision makers and, based on an established standard might transform a discontinuity in a defect.

Discontinuities are interruptions in the typical structure of a weld. They may be a lack of uniformity in the mechanical, metallurgical, or physical characteristics of the material or weld. All welds have discontinuities, but they are not necessarily defects.

A defect, according to AWS (American Welding Society), is a discontinuity or discontinuities, which by nature or accumulated effect (e.g. total porosity or multiple inclusions) renders a part or the whole product unable to meet minimum applicable acceptance standards. This term designates rejectability (Jeffus, 2008).

Discontinuities and defects have to be detected in order to determine the quality of the weld and related to the possible etiology.

\section{AIM}

The purpose of this study was to highlight the visible discontinuities present in the laser welds of dental $\mathrm{Ni}-\mathrm{Cr}$ alloys.

\section{MATERIALS AND METHOD}

Three different Ni-Cr base metal alloys designated for fixed prostheses manufacture were selected for the experiments: Wiron 99: $22.5 \% \mathrm{Cr}, 65 \% \mathrm{Ni}, 9.5 \% \mathrm{Mo},<1 \% \mathrm{Si},<1 \% \mathrm{Fe},<1 \%$
$\mathrm{Nb},<1 \% \mathrm{Ce}$, Wirolloy NB: $25 \% \mathrm{Cr}, 67 \% \mathrm{Ni}, 5 \% \mathrm{Mo}, 1.5 \% \mathrm{Si}$, $<1 \% \mathrm{Mn},<1 \% \mathrm{Nb},<1 \% \mathrm{C},<1 \%$ B (Bego, Bremen, Germany), Heraenium NA: $24 \% \mathrm{Cr}, 59.3 \% \mathrm{Ni}, 10 \% \mathrm{Mo},<2 \% \mathrm{Si},<2 \%$ $\mathrm{Mn},<2 \% \mathrm{Fe},<2 \% \mathrm{Nb}$ (Heraeus Kulzer $\mathrm{GmbH}$, Hanau, Germany).

The filler materials were proper wires based on $\mathrm{Ni}-\mathrm{Cr}$ with a diameter of $0.35 \mathrm{~mm}$.

Experimental metallic plates $(0.8$ × 10 x $20 \mathrm{~mm})$ were achieved by the classical melting-casting laboratory procedure and prepared for welding.

Using these plates, preliminary tests were conducted by laser welding in butt joint configuration, without filler material, bilaterally and with filler material, proper for the base metal, a Ni-Cr welding wire: $22.1 \% \mathrm{Cr}, 63.8 \% \mathrm{Ni}, 9.1 \% \mathrm{Mo}, 1 \% \mathrm{Si}, 1 \%$ $\mathrm{Fe}, 3 \% \mathrm{Nb}$ (Bego, Bremen, Germany).

For laser welding the Nd:YAG laser device Trumpf HL 124P LCU (Trumpf GmbH, Ditzingen, Germania) was selected.

Macroscopic visual inspection was done carefully to assess the defects of the welding rib. Welding rib width, craters on the surface, continuity of the weld, visible cracks, penetration degree of the spot, and any surface inclusions were examined (Fig. 1, 2). Some samples showed visible defects, but other seemed without any discontinuity and were completed with microscopy examinations.

For the experiments a scanning electron microscope (SEM) with integrated EDS system Inspect S + EDAX GENESIS XM 2i (FEI Company, Eindhoven, Netherland) was used.

Electron microscopy images allowed visualization of small discontinuities, which escapes visual inspection.

The examined samples revealed some small cracks in the welding rib, both longitudinal and transverse or oblique. Some start from the main longitudinal cracks, some from the middle spot, others are completely isolated.

Also details of the the weld surface, spots aspect, their overlapping and distribution of filler material could be detected by microscopic analysis (Fig. 3, 4).

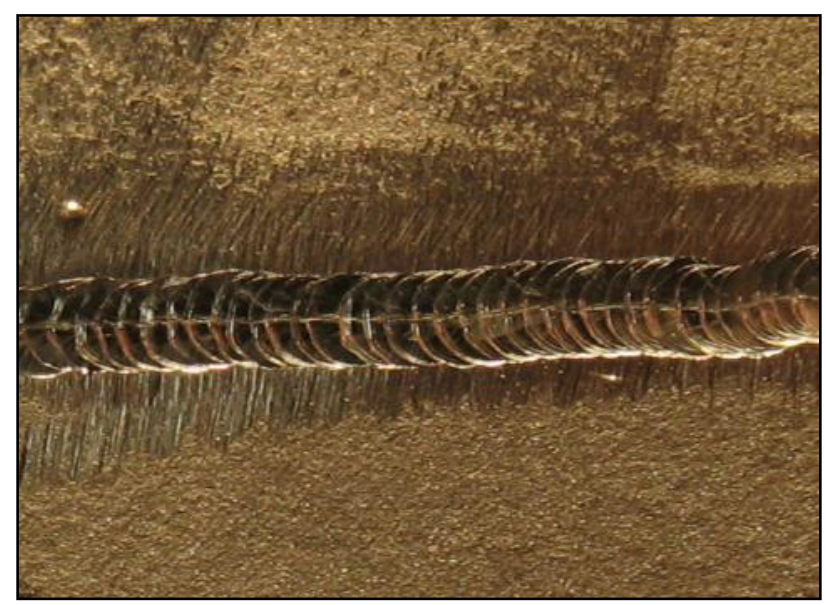

Fig. 1. Aspect of $\mathrm{Ni}-\mathrm{Cr}$ alloy sample (welding without filler material): uniform width of the weld, continues crack along the joining line 


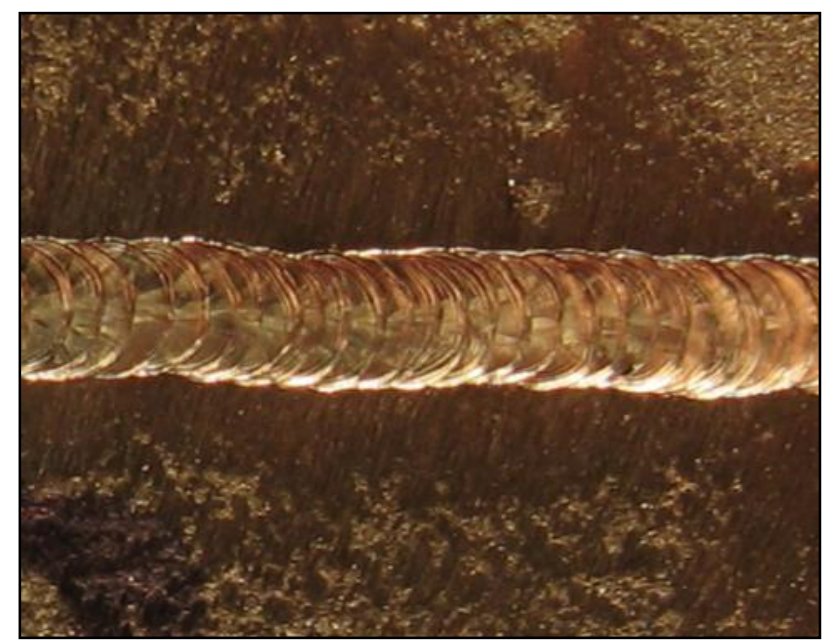

Fig. 2. Aspect of a welded Ni-Cr alloy sample (welding without filler): uniform overlapping of the spots, no visible defects

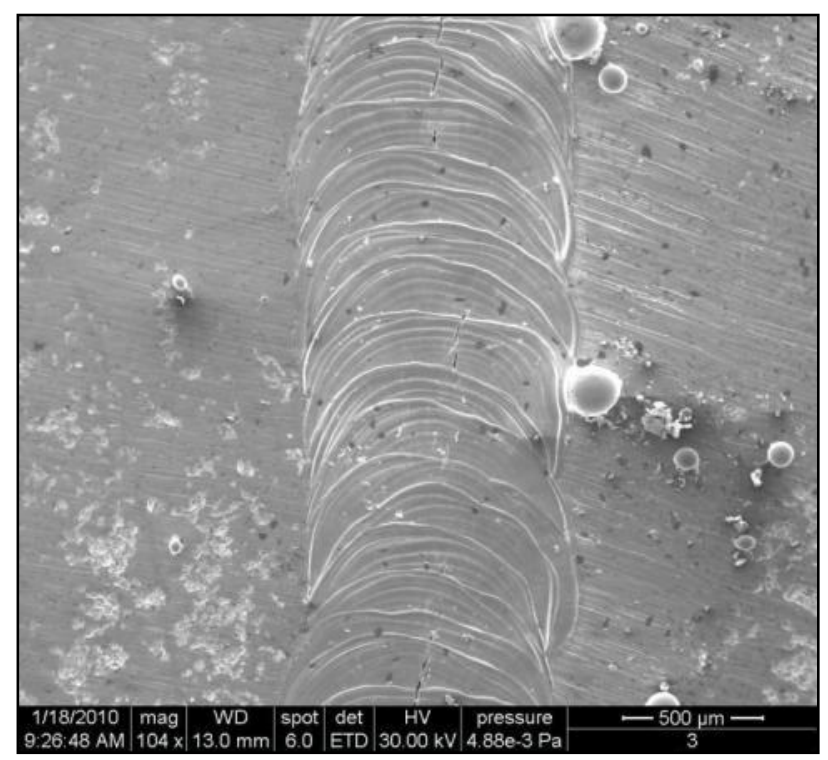

Fig. 3. Electronomicroscopic image of a Ni-Cr alloy welded joints without filler material: short longitudinal cracks on the welding rib (mag 104x)

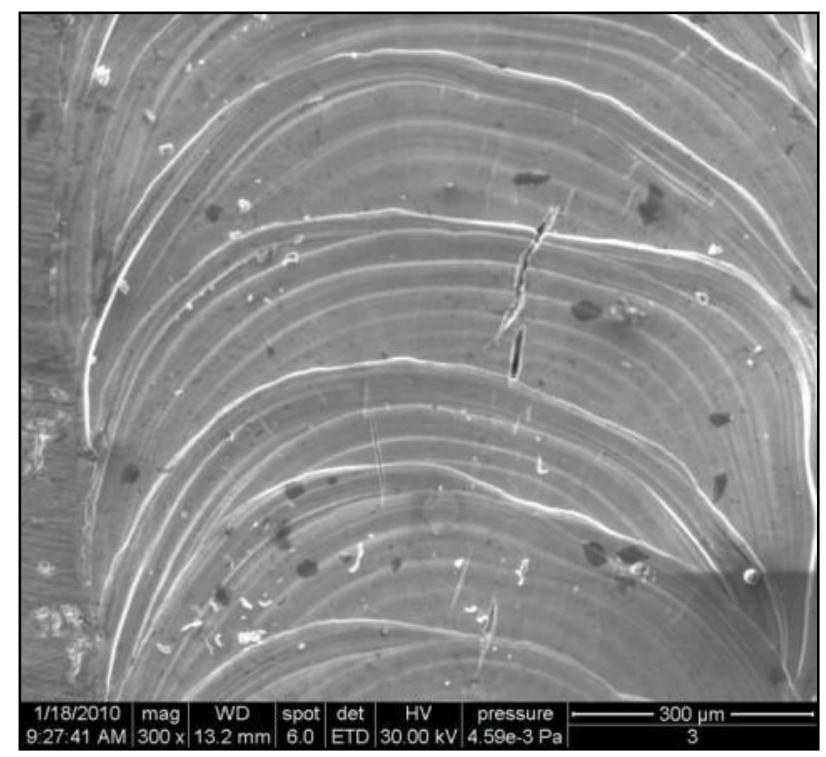

Fig. 4. Electronomicroscopic image of a Ni-Cr alloy welded joints without filler material: short longitudinal cracks on the welding rib (mag 300x)

\section{RESULTS AND DISCUSSIONS}

Making comparison to $\mathrm{Ni}-\mathrm{Cr}$ alloys taken in the experiment and laser welded, after visual analysis, the best welds appear for Heraenium NA alloy, especially with no filler material, but also with filler material.

All samples show compact welding, without cracks, aspect proved by the tests. Welding with filler material is better for NB Wirolloy than for Wiron 99. Penetration is higher. Welding without filler is similar for Wiron 99 and Wirolloy NB. NA Heraenium alloy contains less $\mathrm{Ni}$, and this improved laser welding could be due to this fact.

Welding parameters could be in properly adjust the first stage corresponding to visual assessments (Bertrand et al., 2004; Bertrand \& Poulon-Quintin, 2010). The spot diameter decrease increase the penetration because penetration per unit area is higher at a constant pulse energy (Baba \& Watanabe, 2005).

Welding without filler material needs a space between the two components below $0.1 \mathrm{~mm}$, a spots overlapping of $70 \%$ and welding on both sides (Neumann \& Lindigkeit, 2005).

The welding with filler material is prepared in the form of " $\mathrm{X}$ " and filler material is deposited from deep areas to the surface (Perret et al., 2001).

\section{CONCLUSION}

Laser welds of $\mathrm{Ni}-\mathrm{Cr}$ alloys frameworks for optimizations are higher than those made by other welding processes.

In practice macroscopic visual analysis of weld quality is the only way to test from the experimental complex analysis methods. In the experimental tests it precedes other test methods.

Macroscopic examination allows assessment of the welding rib and the surface aspect. Microscopic analysis allows detecting small discontinuities, which are not visible to the naked eye and revealing details of location, trajectory, morphology and size.

Further studies could reveal the influence of these cracks on the strength of welds from practical point of view.

\section{ACKNOWLEDGEMENTS}

This work was supported by CNCSIS-UEFISCSU, project number PN II-RU TE_217/2010.

\section{REFERENCES}

Baba, N, \& Watanabe, I. (2005). Penetration depth into dental casting alloys by Nd:YAG laser, J Biomed Mater Res B Appl Biomater, 72(1):64-8, ISSN 1552-4973

Bertrand, C.; Le Petitcorps, Y.; Albingre, L. \& Dupuis V. (2004). Optimization of operator and phisical parameters for laser welding of dental materials, $\mathrm{Br}$ Dent $J$, 196(7):413-8, ISSN 0007-0610

Bertrand, C. \&, Poulon-Quintin A. (2010). Proposals for Optimization of Laser Welding in Prosthetic Dentistry. $J$ Prosthodont, 19(1):69-76, ISSN 0893-2174

Jeffus, L. (2008). Welding: Principles and applications, $6^{\text {th }}$ edition. Thomson Delmar Learning, ISBN 978-1-41805275-1, New York

Neumann, M.O. \& Lindigkeit J. (2005). Mechanische Festigkeit von geschweißten EMF-Legierungen, Quintessenz Zahntech, 31(9):966-73, ISSN 0340-4641

Perret, O.; Bizonard, M.; Naudy, Ph.; Pascal, G.; Nore, D. \&Horde, Y.(2001). Characterization of keyhole formed during pulsed Nd:YAG laser interaction with a Ti-6Al-4V metallic target, J Appl Phys, 90:27-30, ISBN 0021-8979 